\title{
Adherence to the Mediterranean diet in Cyprus and its relationship to multi-morbidity: an epidemiological study
}

\author{
Maria Kyprianidou ${ }^{1, *}$, Demosthenes Panagiotakos ${ }^{2} \odot$, Antigoni Faka ${ }^{3}$, \\ Maria Kambanaros ${ }^{4}$, Konstantinos C Makris $^{1}$ and Costas A Christophi ${ }^{1}$ \\ ${ }^{1}$ Cyprus International Institute for Environmental and Public Health, Cyprus University of Technology, Eirinis 95 Street, \\ Limassol 304 1, Cyprus: ${ }^{2}$ Department of Nutrition and Dietetics, School of Health Sciences and Education, Harokopio \\ University, Athens, Greece: ${ }^{3}$ Department of Geography, School of Environment, Geography and Applied Economics, \\ Harokopio University, Athens, Greece: ${ }^{4}$ Department of Rehabilitation Sciences, Cyprus University of Technology, \\ Limassol, Cyprus
}

Submitted 1 June 2020: Final revision received 24 September 2020: Accepted 20 0ctober 2020: First published online 27 0ctober 2020

\begin{abstract}
Objective: To examine the adherence to the Mediterranean diet in the adult general population of Cyprus and assess its relationship with multi-morbidity.

Design: A representative sample of the adult population of Cyprus was selected in 2018-2019 using stratified sampling. Demographics, Mediterranean diet, smoking and physical activity, as well as the presence of chronic, clinical and mental conditions, were collected using a validated questionnaire. Diseases were classified according to the International Classification of Diseases, 10th Revision. Setting: The five government-controlled municipalities of the Republic of Cyprus. Participants: A total of 1140 Cypriot men and women over 18 years.

Results: The average Mediterranean diet score was $15.5 \pm 4.0$ with males and residents of rural regions being more adherent to the Mediterranean diet compared with females and residents of urban regions $(P<0.05)$. Being in the higher tertile of adherence to the Mediterranean diet was associated with lower odds of multi-morbidity compared with the lower tertile, and this result was statistically significant even after adjusting for age, gender, smoking habits and physical activity (OR $=0.68,95 \%$ CI 0.46, 0.99).

Conclusions: The study provides evidence of the adherence to the Mediterranean diet in Cypriot population and its association with multi-morbidity. Adherence to the Mediterranean diet was associated with lower risk of multi-morbidity. Future research would attempt to replicate such results that could add solid pieces of evidence towards meeting some criteria of causality and severity tests; hence, prevention programmes and practice guidelines in Cyprus and elsewhere should take into account those beneficial effects.
\end{abstract}

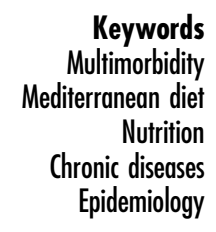

Dietary habits can affect an individual's health throughout life. A healthy diet is preventive of several diet-related noncommunicable diseases and conditions ${ }^{(1)}$. It has been reported that a diet which includes a high consumption of food groups such as fruits and vegetables, whole grains and fish ${ }^{(2)}$ and a low animal-fat consumption lowers the risk of obesity and CVD, for example stroke and heart disease, as well as of CVD risk factors, such as hypertension and hypercholesterolaemia ${ }^{(3)}$, and of neoplastic diseases ${ }^{(4)}$.

The effect of diet on human health has been the subject of investigation in many epidemiological studies, and the Mediterranean diet is the most extensively studied dietary pattern. It was first presented by Ancel Keys in 1950s, and it is characterised by a high intake of olive oil, fruit, nuts, vegetables and cereals, a moderate intake of fish and poultry, a low intake of dairy products, red meat, processed meats, and sweets and wine in moderation consumed with meals ${ }^{(5)}$. In Cyprus, there is a lack about the knowledge of the population's adherence to the Mediterranean diet. Its relationship to human health and particularly $\mathrm{CVD}^{(6,7)}$, other metabolic morbidities ${ }^{(3)}$, some types of cancer $^{(8)}$ and psychological and neurological disorders ${ }^{(9)}$ has also been examined. However, the level of adherence to the Mediterranean diet has been reduced over the past couple 
of decades; this transition in dietary patterns is associated with increased levels in obesity, CVD and diabetes ${ }^{(10)}$.

Multi-morbidity is defined as the co-existence of two or more chronic conditions ${ }^{(11)}$. The increasing prevalence of multi-morbidity observed over the last several years is due primarily to the higher occurrence of chronic diseases $^{(12)}$, particularly in older people ${ }^{(13)}$. It has been reported that $18-30 \%$ of adults live with two or more co-existing conditions ${ }^{(14)}$, with the estimates varying from $10 \%$ to over $90 \%{ }^{(6)}$. Multi-morbidity is very common in the elderly population, among whom in some cases the prevalence was found to be $>60 \%{ }^{(14)}$. Given that chronic illnesses are the leading cause of morbidity worldwide and that the WHO has projected that, by 2030, female and male life expectancy will increase to 85 and 78 years, respectively, the prevalence of multi-morbidity and the number of years lived with chronic diseases is expected to increase even more.

Co-existent conditions can lead to reduced quality of life and can put patients at risk through poly-pharmacy. It can also limit access to therapies and operative interventions and increase the risk of functional limitations and complications in treatment delivery ${ }^{(15)}$. Therefore, identifying factors related to multi-morbidity is quite important. Several epidemiological and demographic characteristics have been linked with the condition, including age $^{(15-17)}$, sex ${ }^{(18)}$, BMI ${ }^{(15)}$, education ${ }^{(17)}$, socio-economic status $^{(15,17,19)}$, quality of life ${ }^{(20)}$, physical activity ${ }^{(15)}$, smoking $^{(21)}$ and psychological factors ${ }^{(20)}$. Healthy diet may also be associated with multi-morbidity, and adherence to the Mediterranean diet could potentially prevent the development of multi-morbidity.

Knowledge about the adherence to Mediterranean diet in a specific population and the factors associated with multi-morbidity in a given population has important implications for prevention, diagnosis, treatment and prognosis strategies. To the best of our knowledge, the association of multi-morbidity with Mediterranean diet has not been previously examined.

Hence, the aim of this study was to examine the adherence of the Mediterranean diet and the relationship between adherence to the Mediterranean diet and multimorbidity in the adult general population of Cyprus.

\section{Methods}

\section{Study design}

This was a cross-sectional study.

\section{Setting}

The study population included men and women of 18 years old or older who are residents of the five governmentcontrolled municipalities of the Republic of Cyprus (i.e. Nicosia, Limassol, Larnaca, Paphos and Ammochostos).
Assuming a precision of $5 \%$ with a true prevalence of multi-morbidity of $30 \%$ in the population, the sample size required for the study was calculated to be 1145 . Participants were recruited in both public areas and in houses throughout Cyprus, between May 2018 and June 2019, using convenience sampling, but with an effort to avoid any selection bias (i.e. enrolment or exclusion of participants with specific characteristics); Nicosia ( $43 \%$ of the total Cypriot population), Limassol (27\%), Larnaca (15\%), Paphos (10\%) and Ammochostos (5\%). Trained researchers approached people, and after explaining the purpose of the study, they would point out that their participation is anonymous and that they could withdraw their participation at any point. The response rate was $90 \%$, and the final study sample did not significantly differ from the general population in terms of region, age and gender (all $P$-values $>0.05$ ). More details of the study are presented elsewhere ${ }^{(22)}$.

\section{Participants' characteristics}

Trained researchers collected the information using a standardised questionnaire which included data on sociodemographic characteristics (e.g. age, gender, marital status, education and income), lifestyle habits (e.g. smoking, diet and physical activity), BMI and a medical history which was obtained via a face-to-face interview.

\section{Dietary assessment}

Dietary assessment was based on a validated semiquantitative $\mathrm{FFQ}^{(23)}$. Participants' total daily energy and macronutrient (i.e. total carbohydrate, total fat, animaland plant-based protein) intake was derived through their responses to the FFQ based on standard food databases. The validation of the FFQ was based on participants from Athens, Greece ${ }^{(23)}$, but the questionnaire has been found to provide an acceptable assessment of long-term dietary intakes in the general population, in various countries and regions. Moreover, it is known that the Cypriot population has similar characteristics with the Greek population, including dietary habits, as both Greeks and Cypriots share common foods, cooking practices and eating behaviours. The FFQ included specific local food groups, such as Cyprus local cheese (halloumi) and other local products. The questionnaire contains extensive information on the dietary habits of the participants, and it includes the consumption of eleven food groups which follow the rationale of the Mediterranean dietary pattern ${ }^{(24)}$ : non-refined cereals, fruits, vegetables, legumes, potatoes, fish, meat and meat products, poultry, full-fat dairy products, as well as olive oil and alcohol intake. Adherence to the Mediterranean diet was evaluated on the basis of the MedDietScore ${ }^{(24)}$ which has a range of $0-55$, with higher values indicating greater adherence to the Mediterranean diet. For the consumption of items presumed to be close to this pattern, scores were assigned as $0,1,2,3,4$ and 5, similar to Panagiotakos et al., when a participant 
reported never/rarely, 1-3 times/month, 1-2 times/week, 3-6 times/week, 1 time/d and more than 2 times/d, respectively. For the consumption of foods presumed to be away from this pattern, scores were assigned in the reverse order.

\section{Medical assessment}

The medical history part of the questionnaire included forty-seven chronic diseases of all human systems. Diseases were coded according to the International Classification of Diseases (Appendix I). The researchers completed that part of the questionnaire via a face-to-face interview, using the question 'Have you ever been diagnosed by a physician with any of the following chronic diseases? Choose all that apply'. Multi-morbidity was subsequently defined 'as any combination of chronic disease with at least one acute or chronic disease or biopsychosocial factor or somatic risk factor' ${ }^{(25)}$.

\section{Spatial analysis}

Using the different districts of Cyprus as a basis, we performed spatial analysis to evaluate the adherence to the Mediterranean diet in the general population in Cyprus. The analysis was done using the ArcGIS version 10.4 (ESRI Inc.).

\section{Statistical analysis}

Continuous variables (such as age, weight, height and BMI) are presented as mean \pm SD and categorical variables (such as age group, gender, geographical area, residency, marital status, educational level, salary category, physical activity level, smoking, obesity group, adherence to Mediterranean diet levels) as absolute and relative (\%) frequencies. Associations between normally distributed variables and the MedDietScore tertiles were evaluated using the one-way ANOVA method, whereas for nonnormally distributed variables, the non-parametric KruskalWallis test was used instead. The correlations between covariates were examined using the Pearson and Spearman correlations, as appropriate. The CochranArmitage test for trend was also used in order to assess trends in categorical variables. Linear regression was applied to attend effects of several factors on the Mediterranean diet score. Logistic regression models of multi-morbidity and adherence to Mediterranean diet were constructed after adjusting for possible confounders, including age, gender, smoking and physical activity status. OR and the corresponding $95 \% \mathrm{CI}$ are reported. Interactions terms were tested using the Wald test. The fit of the model was assessed using the Hosmer-Lemeshow goodness of fit test. All statistical tests performed were two-sided with the statistical significance level set at $\alpha=0 \cdot 05$. Statistical analysis was conducted using STATA 14.0 (Stata Corp.).

\section{Results}

\section{Participants' characteristics}

The mean age of the 1140 participants was $41 \pm 17$ years (Table 1). It was $40 \pm 16$ years for 642 women and $42 \pm 18$ years for 497 men. In addition, $54 \%$ were married, $64 \%$ had completed a higher education and $40 \%$ were private employees. The overall mean BMI was $25 \pm 5 \mathrm{~kg} / \mathrm{m}^{2}$ and specifically $24.9 \pm 4.8 \mathrm{~kg} / \mathrm{m}^{2}$ for women and $26.4 \pm$ $4.0 \mathrm{~kg} / \mathrm{m}^{2}$ for men.

\section{Mediterranean diet adberence and spatial analysis}

The median Mediterranean diet score of the participants was 15 (quartiles, $\mathrm{q}_{1}=13, \mathrm{q}_{3}=18$ ) with the maximum score being 34 . The tertiles of adherence to a Mediterranean diet were estimated, dividing the sample into three approximately equal size subgroups as follows: low adherence (score $<13$ ), moderate adherence (score 13-17) and high adherence (score $>17$ ). More females were in the low adherence tertile (37\% v. 27\%) than the high adherence one compared with males ( $27 \% v .35 \%)$. Similarly, a higher percentage of rural residents and physically active participants was in the high adherence tertile compared with the urban residents and physically inactive participants, respectively (both $P<0.05$ ). Other characteristics, such as age, geographical area and BMI, were similar among the three tertiles of adherence to the Mediterranean diet (Table 1).

Mapping Mediterranean diet adherence across Cypriot districts exhibited higher rates of high adherence in Ammochostos and Paphos (39 and 37\%, respectively), and lower rates in the other districts (Fig. 1a) while rates of moderate adherence were similar in Nicosia and Limassol (Fig. 1b). It is important to mention that Ammochostos is primarily a rural area as well as Paphos in its largest area. The lowest adherence to Mediterranean diet was seen in the capital of Cyprus, Nicosia district (Fig. 1a and 1c). Rural areas were characterised by higher adherence to Mediterranean diet. Specifically, high adherence was $10 \%$ higher in rural areas than urban areas $(38 \% v .28 \%)$, which were characterised primarily with low and moderate adherence (38 and $34 \%$, respectively) (Fig. 1d).

Being divorced/widowed and having completed a secondary education was negatively associated with the Mediterranean diet score $(P<0.05)$. On the other hand, being male, living in Limassol or Paphos, living in rural area and being physically active was positively associated with the Mediterranean diet score $(P<0.05)$ (Table 2$)$.

\section{Associations of Mediterranean diet and multi-morbidity}

The median number of conditions per participant was 1 (quartiles, $\mathrm{q}_{1}=0$ and $\mathrm{q}_{3}=2$ ) with the maximum number being 12. Figure 2 illustrates the distribution of 


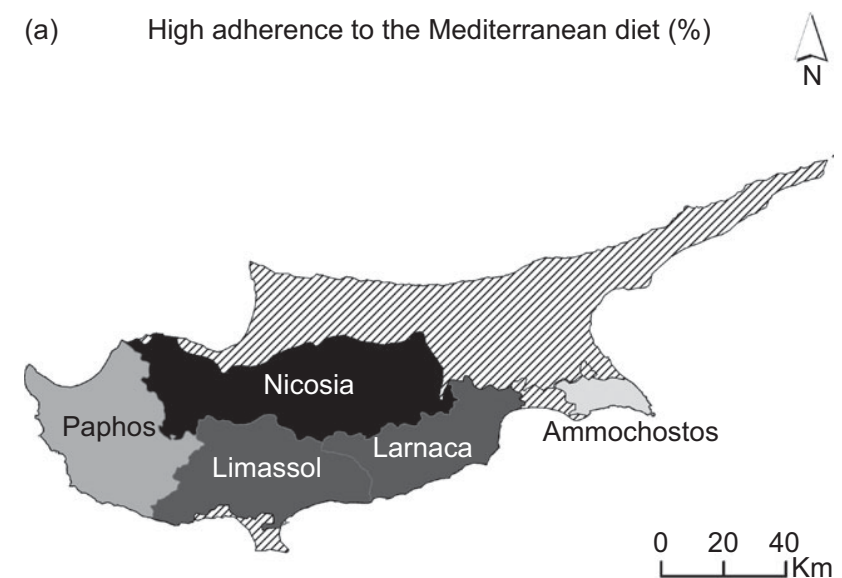

(c)

Low adherence to the Mediterranean diet (\%)

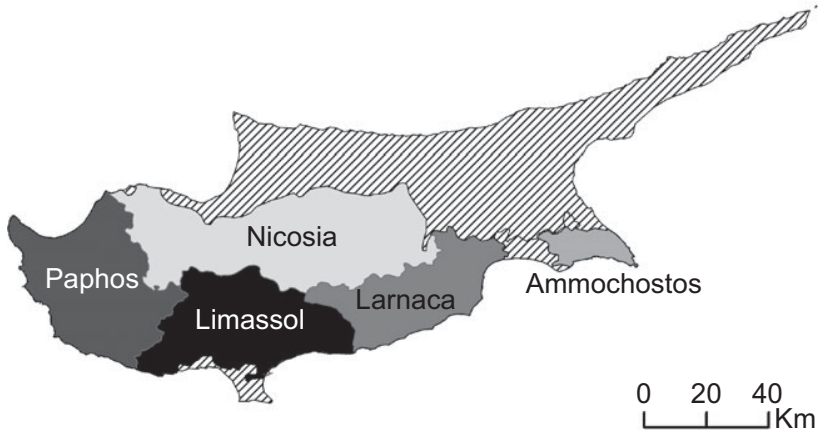

(b)

Moderate adherence to the Mediterranean diet (\%)

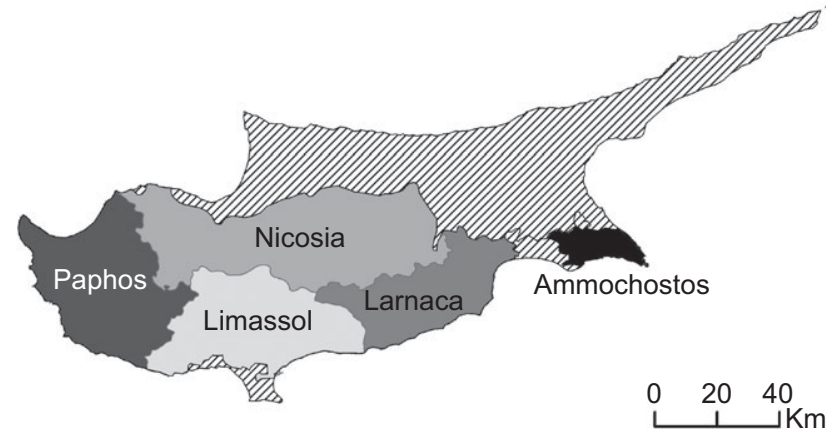

(d) Adherence to the Mediterranean diet in urban and rural areas

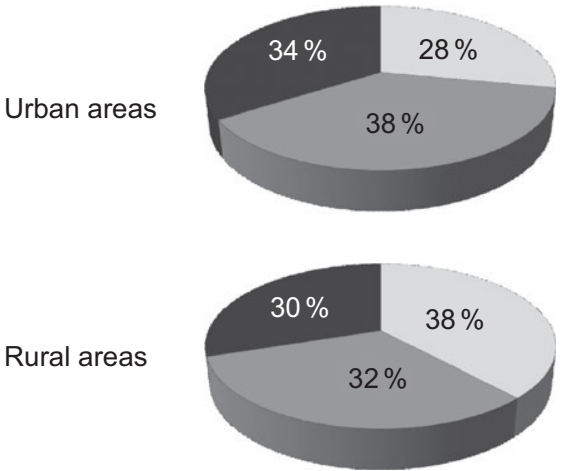

Fig. 1 Spatial analysis of Mediterranean diet adherence by region of residence and level of urbanicity. (a) High adherence to the Mediterranean diet (\%). $\square, 39 ; \square, 37 ; \square, 33 ; \square, 26$; שाM, Non-government controlled areas. (b) Moderate adherence to the Mediterranean diet (\%). $\square, 39 ; \square, 38 ; \square, 35 ; \square, 34 ;$ DाM, 27;, Non-government controlled areas. (c) Low adherence to the Mediterranean diet (\%). $\square, 36 ; \square, 34 ; \square, 32 ; \square, 29 ;$ पाM, $28 ; \square$, Non-government controlled areas. (d) Adherence to the Mediterranean diet in urban and rural areas (\%). $\square$, High; $\square$, moderate; $\square$, low

multi-morbidities by Mediterranean diet adherence. Among the three levels of Mediterranean diet adherence, the highest number of multi-morbidities was identified in the low adherence group, whereas the moderate and high adherence groups seem to have overall a lower number of multi-morbidities.

Respondents who were in the high adherence group had a lower risk of multi-morbidity compared with respondents in the low adherence group (Table 3, unadjusted $\mathrm{OR}=0.64,95 \%$ CI $0.45,0.90)$. More specifically, participants in the high MedDietScore tertile presented about $32 \%$ lower risk of multi-morbidity, compared with those in the low MedDietScore tertile. The relation remained statistically significant even after adjusting for age, gender, smoking habits and physical activity (Table 3, OR $=0.68$, $95 \%$ CI 0.46, 0.99).

Although the interaction term between sex and Mediterranean diet score was not statistically significant, historical data suggest that both morbidities and dietary habits may differ between men and women. Therefore, we stratified the analysis by sex, and we found that the association between MedDietScore tertiles and multi-morbidity statistical significant only in the group of females (Table 3, unadjusted $\mathrm{OR}=0 \cdot 57,95 \%$ CI 0.36, 0.90).

Hierarchical multivariable logistic regression models were used adjusting for social and demographic indicators. First, we adjusted for age and sex and then added lifestyle habits including smoking habits and physical activity level and finally socio-economic and demographic characteristics including educational and marital status, geographical area and residency (Fig. 3) indicated that the adjusted odds of multi-morbidity were consistently lower and statistically significant for respondents in the high adherence group than the other two groups.

Furthermore, factors including age, sex and educational status were statistically significant predictors for the presence of multi-morbidity in an individual. Specifically, males had lower adjusted odds of multi-morbidity (OR $=0.56$; $95 \%$ CI $0.41,0.78)$, and the risk was 1.06 times higher for every 1-year increase in age. We also reported that 
Table 1 Cypriot population's adherence to Mediterranean diet

\begin{tabular}{|c|c|c|c|c|c|c|c|c|c|}
\hline \multirow[b]{3}{*}{ Characteristics } & \multicolumn{8}{|c|}{ Mediterranean diet score } & \multirow[b]{3}{*}{$P$-value } \\
\hline & \multicolumn{2}{|c|}{ Overall ( $n$ 1123) } & \multicolumn{2}{|c|}{ Low (n 367) } & \multicolumn{2}{|c|}{$\begin{array}{l}\text { Moderate } \\
(n 413)\end{array}$} & \multicolumn{2}{|c|}{ High (n 343) } & \\
\hline & Median & (Q1, Q3) & $n$ & $\%$ & $n$ & $\%$ & $n$ & $\%$ & \\
\hline Mediterranean diet score* & 15 & 13,18 & 12 & 10,13 & 16 & 15,16 & 20 & 18,21 & \\
\hline Age group (years) & & & & & & & & & 0.26 \\
\hline $18-24$ & 16 & 13,18 & 45 & $27 \cdot 8$ & 65 & $40 \cdot 1$ & 52 & $32 \cdot 1$ & \\
\hline $25-44$ & 15 & 13,18 & 170 & 32.9 & 184 & $35 \cdot 6$ & 163 & 31.5 & \\
\hline $45-64$ & 15 & 12,18 & 115 & $37 \cdot 2$ & 106 & $34 \cdot 3$ & 88 & $28 \cdot 5$ & \\
\hline $65+$ & 16 & 13,18 & 37 & $27 \cdot 4$ & 58 & 43.0 & 40 & $29 \cdot 6$ & \\
\hline Sex & & & & & & & & & $<0.01$ \\
\hline Male & 16 & 13,19 & 132 & $26 \cdot 8$ & 187 & 38.0 & 173 & $35 \cdot 2$ & \\
\hline Female & 15 & 12,18 & 235 & 37.3 & 226 & 35.9 & 169 & $26 \cdot 8$ & \\
\hline Geographical area & & & & & & & & & 0.10 \\
\hline Nicosia & 15 & 12,18 & 178 & $36 \cdot 4$ & 184 & 37.6 & 127 & $26 \cdot 0$ & \\
\hline Limassol & 16 & 13,19 & 86 & 28.4 & 118 & 38.9 & 99 & $32 \cdot 7$ & \\
\hline Larnaka & 15 & 13,18 & 54 & 31.6 & 60 & $35 \cdot 1$ & 57 & 33.3 & \\
\hline Paphos & 16 & 13,19 & 32 & 29.4 & 37 & 33.9 & 40 & $36 \cdot 7$ & \\
\hline Ammochostos & 16 & 13,19 & 17 & 34.7 & 13 & $26 \cdot 5$ & 19 & $38 \cdot 8$ & \\
\hline Residency & & & & & & & & & 0.01 \\
\hline Urban & 15 & 13,18 & 287 & 33.8 & 323 & 38.0 & 239 & $28 \cdot 2$ & \\
\hline Rural & 16 & 13,18 & 79 & $29 \cdot 6$ & 87 & 32.6 & 101 & 37.8 & \\
\hline Marital status & & & & & & & & & $<0.01$ \\
\hline Married & 16 & 13,18 & 178 & $29 \cdot 2$ & 242 & 39.7 & 189 & $31 \cdot 0$ & \\
\hline Unmarried & 16 & 13,19 & 132 & $32 \cdot 1$ & 144 & $35 \cdot 0$ & 135 & 32.9 & \\
\hline Divorced/Widowed & 13 & $10 \cdot 5,16$ & 54 & $56 \cdot 3$ & 25 & $26 \cdot 0$ & 17 & $17 \cdot 7$ & \\
\hline Educational status & & & & & & & & & 0.34 \\
\hline Primary & 16 & 13,18 & 18 & $27 \cdot 3$ & 25 & 37.9 & 23 & $34 \cdot 8$ & \\
\hline Secondary & 15 & 12,18 & 122 & 36.5 & 121 & $36 \cdot 2$ & 91 & $27 \cdot 3$ & \\
\hline Higher & 15 & 13,18 & 224 & 31.3 & 265 & 37.0 & 227 & 31.7 & \\
\hline Salary & & & & & & & & & 0.24 \\
\hline Low & 15 & 13,18 & 82 & 34.9 & 85 & $36 \cdot 2$ & 68 & $28 \cdot 9$ & \\
\hline Middle & 15 & 13,18 & 190 & 34.4 & 191 & $34 . \overline{5}$ & 172 & $31 \cdot 1$ & \\
\hline High & 16 & 13,18 & 93 & 28.5 & 135 & 41.4 & 98 & $30 \cdot 1$ & \\
\hline Physically active & & & & & & & & & $<0.01$ \\
\hline Yes & 16 & 13,19 & 155 & $29 \cdot 1$ & 192 & $36 \cdot 1$ & 185 & 34.8 & \\
\hline No & 15 & 12,18 & 210 & $36 \cdot 0$ & 217 & $37 \cdot 2$ & 156 & $26 \cdot 8$ & \\
\hline Current smoker & & & & & & & & & 0.37 \\
\hline Yes & 15 & 13,18 & 141 & $35 \cdot 3$ & 140 & $35 \cdot 1$ & 118 & 29.6 & \\
\hline No & 16 & 13,18 & 224 & $31 \cdot 2$ & 271 & $37 \cdot 8$ & 222 & $31 \cdot 0$ & \\
\hline BMI group & & & & & & & & & 0.56 \\
\hline Underweight & 16 & 13,19 & 14 & 34.2 & 12 & $29 \cdot 3$ & 15 & $36 \cdot 6$ & \\
\hline Normal & 15 & 13,18 & 176 & 31.7 & 210 & 37.8 & 170 & 30.6 & \\
\hline Overweight & 15 & 13,18 & 115 & 32.4 & 139 & 39.2 & 101 & 28.4 & \\
\hline Obese & $15 \cdot 5$ & 12,18 & 56 & $36 \cdot 8$ & 47 & 30.9 & 49 & $32 \cdot 2$ & \\
\hline
\end{tabular}

*Median (Q1, Q3).

people who completed a secondary education had lower adjusted odds of multi-morbidity (OR $=0.49 ; 95 \%$ CI $0.25,0.96)$ compared with those who completed only primary education.

\section{Discussion}

This population-based study of the general adult Cypriot population provided, to the best of our knowledge, the first evidence of the relationship between adherence to the Mediterranean diet and multi-morbidity. The results suggest that higher adherence to the Mediterranean diet is associated with lower odds of multi-morbidity. Adopting a dietary pattern, which is close to the Mediterranean diet, is beneficial and would help in reducing the risk of multi-morbidity. This is an important public health message and reinforces the evidence available for the positive impact of a traditional Mediterranean diet.

The study suggests that the Cypriot population is moving away from the traditional Mediterranean diet something that is consistent with other studies which investigated the adherence to Mediterranean diet in other Mediterranean countries ${ }^{(10,26)}$ and with an earlier review ${ }^{(27)}$ for two related Greek-speaking Mediterranean populations, namely the Greek and Cypriot populations. We observed differences in the adherence to the Mediterranean diet between males and females, between the residents of urban and rural regions, and among marital status categories, though we did not observe differences among the four age 


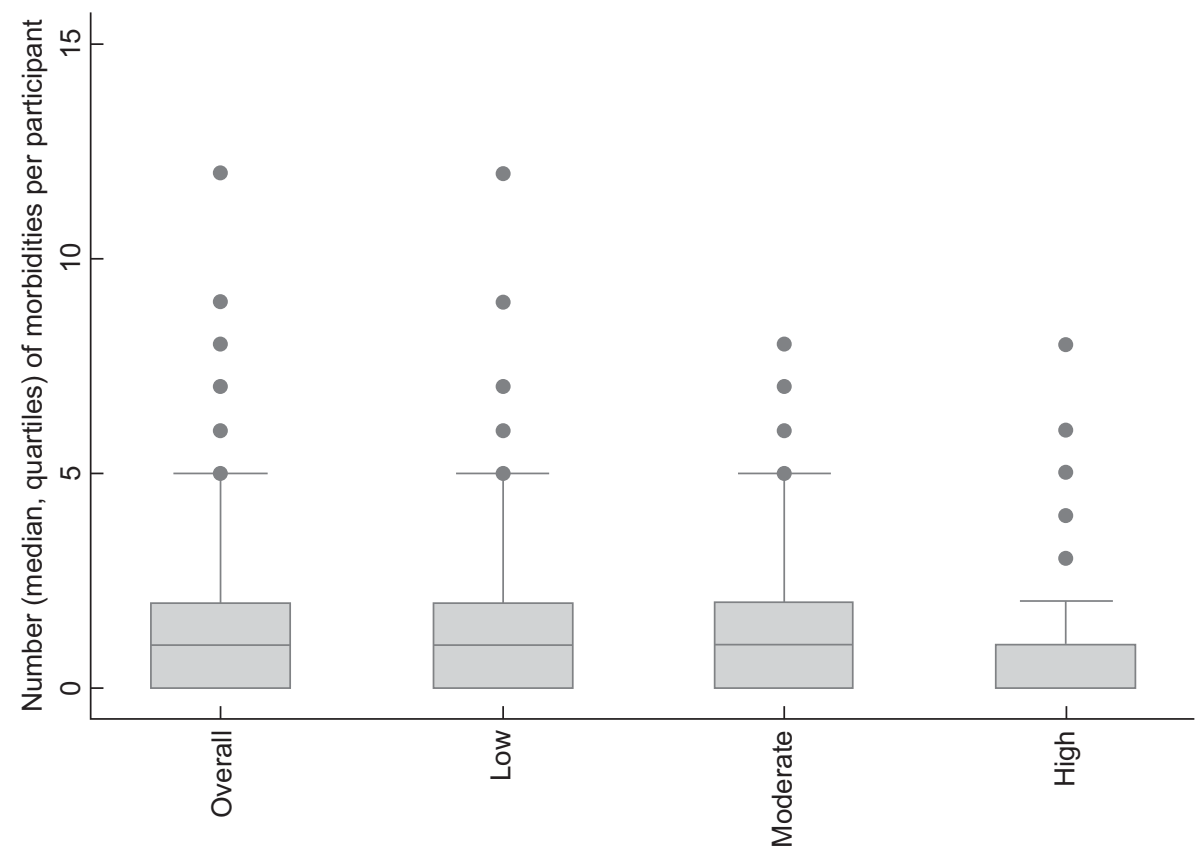

Fig. 2 Distribution of multi-morbidities overall and by Mediterranean diet tertiles

Table 2 Multivariate linear regression for the factors affecting level of the Mediterranean diets score in Cypriot population

\begin{tabular}{|c|c|c|c|c|}
\hline & $\beta$-Coefficient & $95 \% \mathrm{Cl}$ & Standardised $\beta$-coefficient & $P$-value \\
\hline \multicolumn{5}{|l|}{ Age group (years) } \\
\hline $18-24$ & Ref & & Ref & \\
\hline $25-44$ & -0.56 & $-1.44,0.33$ & -0.07 & 0.22 \\
\hline $45-64$ & -0.23 & $-1.27,0.80$ & -0.03 & 0.66 \\
\hline $65+$ & -0.30 & $-1.57,0.96$ & -0.02 & 0.64 \\
\hline \multicolumn{5}{|l|}{ Sex } \\
\hline Female & Ref & & Ref & \\
\hline Male & 0.96 & $0.42,1.50^{*}$ & $0.12^{*}$ & $<0.01$ \\
\hline \multicolumn{5}{|l|}{ Geographical area } \\
\hline Nicosia & Ref & & Ref & \\
\hline Limassol & 0.98 & $0.40,1.56^{*}$ & $0.11^{*}$ & $<0.01$ \\
\hline Larnaka & 0.53 & $-0.19,1.25$ & 0.05 & 0.150 \\
\hline Paphos & 0.89 & $0.05,1.74^{*}$ & $0.07^{\star}$ & 0.038 \\
\hline Ammochostos & 0.94 & $-0.28,2 \cdot 16$ & 0.05 & 0.129 \\
\hline \multicolumn{5}{|l|}{ Residency } \\
\hline Urban & Ref & & Ref & \\
\hline Rural & 0.71 & $0 \cdot 12,1 \cdot 31^{*}$ & $0.08^{*}$ & 0.018 \\
\hline \multicolumn{5}{|l|}{ Marital status } \\
\hline Married & Ref & & Ref & \\
\hline Unmarried & -0.25 & $-0.91,0.41$ & -0.03 & 0.451 \\
\hline Divorced/widowed & $-2 \cdot 12$ & $-3 \cdot 00,-1 \cdot 24^{*}$ & $-0.15^{\star}$ & $<.001$ \\
\hline \multicolumn{5}{|l|}{ Educational status } \\
\hline Primary & Ref & & Ref & \\
\hline Secondary & -1.58 & $-2 \cdot 83,-0 \cdot 34^{*}$ & $-0.18^{*}$ & 0.013 \\
\hline Higher & -1.25 & $-2.56,0.05$ & -0.15 & 0.059 \\
\hline \multicolumn{5}{|l|}{ Salary } \\
\hline Low & Ref & & Ref & \\
\hline Middle & 0.09 & $-0.62,0.79$ & 0.01 & 0.809 \\
\hline High & 0.24 & $-0.61,1.08$ & 0.03 & 0.585 \\
\hline \multicolumn{5}{|l|}{ Physically active } \\
\hline No & Ref & & Ref & \\
\hline Yes & 0.74 & $0.25,1.23^{*}$ & $0.09^{*}$ & $<0.01$ \\
\hline \multicolumn{5}{|l|}{ Current smoker } \\
\hline No & Ref & & Ref & \\
\hline Yes & -0.20 & $-0.71,0.32$ & -0.02 & 0.457 \\
\hline \multicolumn{5}{|l|}{ BMI group } \\
\hline Normal & Ref & & Ref & \\
\hline Underweight & 0.37 & $-0.88,1.62$ & 0.02 & 0.562 \\
\hline Overweight & -0.30 & $-0.87,0.27$ & -0.04 & 0.296 \\
\hline Obese & -0.49 & $-1.25,0.27$ & -0.04 & 0.209 \\
\hline
\end{tabular}

${ }^{*} P<0.05$ 
Secondary vs primary education

Higher vs primary education

Unmarried vs married

Divorced/Widow vs married

Limassol vs Nicosia

Larnaka vs Nicosia

Paphos vs Nicosia

Ammochostos vs Nicosia

Rural vs urban

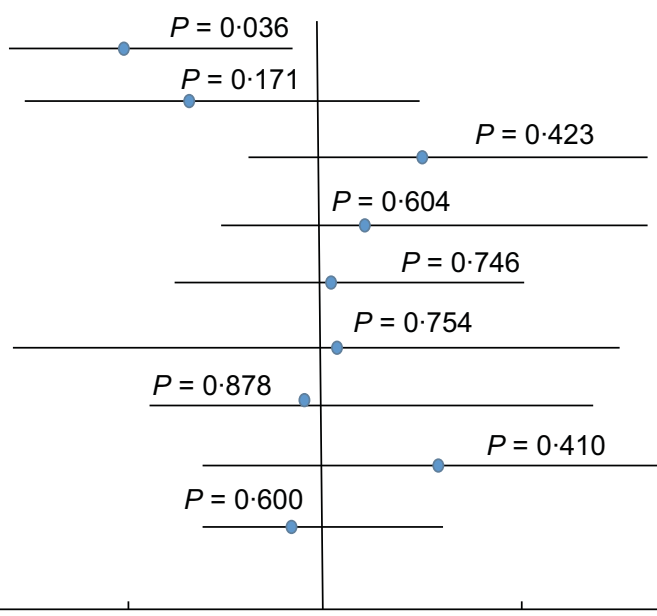

0.5

$1 \cdot 5$
OR of Mediterranean diet adherence on multi-morbidity

$2.5 \quad$ Upper $50 \%$

Fig. 3 (colour online) OR ( $95 \% \mathrm{Cl}$ ) of MedDietScore group tertiles in relation to multi-morbidity presence adjusting for (a) educational status, (b) marital status, (c) geographical area and (d) residency

Table 3 Nested total and sex-based sensitivity logistic regression analysis to evaluate the association of level of adherence to Mediterranean diet (defined through MedDietScore) with multi-morbidity presence ( $n$ 1123)

\begin{tabular}{|c|c|c|c|c|c|c|}
\hline & \multicolumn{2}{|c|}{ Total (n 1122) } & \multicolumn{2}{|c|}{ Female ( $n$ 630) } & \multicolumn{2}{|c|}{ Male ( $n$ 492) } \\
\hline & OR & $95 \% \mathrm{Cl}$ & OR & $95 \% \mathrm{Cl}$ & OR & $95 \% \mathrm{Cl}$ \\
\hline \multicolumn{7}{|c|}{$\begin{array}{l}\text { Model 1: Crude model } \\
\text { MedDietScore tertiles }\end{array}$} \\
\hline Low & Ref & & Ref & & Ref & \\
\hline Moderate & 0.85 & $0.62,1.16$ & 0.71 & $0.48,1.07$ & 1.23 & $0.72,2.08$ \\
\hline High & 0.64 & $0.45,0.90^{\star}$ & 0.57 & $0.36,0.90^{*}$ & 0.87 & $0.50,1.52$ \\
\hline \multicolumn{7}{|c|}{ Model 2: age (sex) } \\
\hline \multicolumn{7}{|c|}{ MedDietScore tertiles } \\
\hline Low & Ref & & Ref & & Ref & \\
\hline Moderate & 0.85 & $0.60,1 \cdot 20$ & 0.74 & $0.48,1.13$ & 1.05 & $0.57,1.94$ \\
\hline High & 0.65 & $0.44,0.95^{\star}$ & 0.61 & $0.38,0.99^{*}$ & 0.71 & $0.37,1.36$ \\
\hline \multirow{2}{*}{\multicolumn{7}{|c|}{$\begin{array}{l}\text { Model 3: Model } 2 \text { plus smoking habits and physical activity } \\
\text { MedDietScore tertiles }\end{array}$}} \\
\hline & & & & & & \\
\hline Low & Ref & & Ref & & Ref & \\
\hline Moderate & 0.88 & $0.62,1.25$ & 0.76 & $0.49,1.18$ & $1 \cdot 10$ & $0.60,2.04$ \\
\hline High & 0.68 & $0.46,0.99^{\star}$ & 0.63 & $0.39,1.02$ & 0.77 & $0.40,1.48$ \\
\hline
\end{tabular}

OR and their corresponding $95 \% \mathrm{Cl}$ were obtained from logistic regression analysis.

${ }^{\star} P<0.05$.

groups considered. The population overall had a moderate to low adherence to the Mediterranean diet with the maximum score being 34; it seems that even though in general the association of moderate $v$. low adherence with multi-morbidity is in the expected direction it does not reach statistical significance.

It is true that there is the perception that older people follow the traditional dietary patterns, including Mediterranean diet ${ }^{(28,29)}$ more than younger people, something though that was not confirmed in our study. In 2005, a study in Cyprus ${ }^{(30)}$ reported that the Mediterranean diet score in the elderly was higher and that more than nine out of ten of the participants in that age group reported that they followed that pattern for at least 30-40 years of their life. It seems that in 2020, none of the study age groups follows the traditional Mediterranean diet to a large extent, since all age groups had score lower than 17 , which is considered low adherence to Mediterranean diet.

We have observed differences in the adherence to the Mediterranean diet between males and females, and specifically, we found that men's adherence to Mediterranean diet was higher than women's which is in agreement with other studies ${ }^{(10,31)}$ but different than the ATTICA study in Greece $^{(32)}$. Given that the Mediterranean diet decreases the risk of CVD, CHD and stroke ${ }^{(6,7)}$ and that in our sample more men than women reported having at least one CVD (30\% v. 20\%), this may play a role for the higher men's adherence to Mediterranean diet. Furthermore, a higher percentage of men aged $65+$ years were in high adherence to Mediterranean diet tertile compared with women with the 
same age ( $16 \% v .7 \%)$, something that support the previous statement.

Although we did not identify statistically significant differences of the adherence to Mediterranean diet among the five geographical areas of Cyprus, we found statistically significant differences between the residents of urban and rural regions with people who lived in rural areas having better adherence. Nowadays, diets are changing due to many reasons including urbanisation ${ }^{(33)}$, an increase in consumption of animal foods, sugar, salt, fats, oils, refined grains and processed foods ${ }^{(33)}$. People living in cities tend to consume more energies many of them from carbohydrates, sugary snacks and processed foods ${ }^{(34)}$, which are widely available in urban areas.

Regarding the adherence of Mediterranean diet of the Cypriot population among several socio-economic factors, we found that divorced/widowed people did not adhere to that dietary habits compared with married and unmarried people, a finding which agrees with other epidemiological studies $^{(35,36)}$. It has been reported that divorced/widowed people did not eat as well as unmarried people $\mathrm{e}^{(37)}$ and that single people including unmarried, divorced, separated and widowed individuals were less likely to consume high fruit and vegetables ${ }^{(38)}$. Although we did not find any statistically significant differences among educational status and Mediterranean diet, we found difference among the salary levels with the higher adherence to Mediterranean diet reporting in high income people which was not statistically significant. Furthermore, people who were physically active and not current smokers had a higher Mediterranean diet score, while obese and overweight people's adherence to Mediterranean diet was smaller than people who classified as normal weight.

The possible health benefits of Mediterranean diet have been documented before for a series of cardiovascular outcomes, for example CHD and stroke ${ }^{(6,7)}$. It has also been suggested that the Mediterranean diet has a positive effect on components of metabolic syndrome like waist circumference, HDL-cholesterol, TAG, systolic and diastolic blood pressure and glucose ${ }^{(28)}$. In Cyprus, it has been reported that adherence to a Mediterranean diet among elderly people was associated with reduced odds of having hypercholesterolaemia, hypertension, diabetes and obesity $^{(30)}$.

The mechanism by which Mediterranean diet may be protective against multi-morbidity is largely unknown. However, we could hypothesise that Mediterranean diet may be protective because of the possible anti-oncogenic actions of the oleic acid in olive oil ${ }^{(39)}$, the many other antioxidants in plant foods ${ }^{(40)}$, and the advantageous effects of the diet on blood lipids ${ }^{(39)}$.

Our study has some limitations. First, the cross-sectional design of the study means that only associations between the groups of interest could be examined and not causal relationships. Furthermore, the severity of the disease is not taken into account, and all chronic diseases included in the study were provided directly by the participants based on diagnosis by a physician and were given equal weight in the calculation of multi-morbidity, though this is commonly used in studies of multi-morbidity. At the same time, the study has several strengths as this is a large population-based study using a representative sample of both men and women from all ages (18+ years) and geographical areas of Cyprus. Other strengths include the collection of detailed data using a validated questionnaire with information on the presence of forty-seven chronic conditions and the participants' dietary habits, including the consumption of eleven food groups: non-refined cereals, fruits, vegetables, legume, potatoes, fish, meat and meat products, poultry, full-fat dairy products, olive oil and alcohol intake as well as information.

This study provides the first evidence of an association between Mediterranean diet and multi-morbidity. Low adherence to the Mediterranean diet was associated with higher odds of multi-morbidity. Future prevention programmes and practice guidelines in Cyprus and elsewhere should take into account the beneficial effects of Mediterranean diet on multi-morbidity.

\section{Acknowledgements}

Acknowledgements: The authors specially thank all participants who voluntarily contributed to the study and provided the requested information. The authors would also like to thank the trained researchers of the study who assisted in the data collection process throughout the five municipalities of Cyprus. Financial support: None. Conflict of interest: None to declare. Authorship: M.K. contributed in the conception and design of the study, the acquisition and analysis of data and writing of the first draft. C.A.C. and D.P. contributed in the formulation of the research hypothesis, design of the study, supervision, interpretation of the results and in critically editing the original draft. K.C.M. and M.K. contributed in the design of the study and in reviewing and editing the manuscript. A.F. contributed in data analysis and in editing the manuscript. All authors critically reviewed earlier drafts of the manuscript and approved the final version. Ethics of buman subject participation: This study was conducted according to the guidelines laid down in the Declaration of Helsinki, and all procedures involving study participants were approved by the Cyprus National Bioethics Committee (CNBC) (EEBK EП 2018.01.123). The application, along with all relevant questionnaires, submitted to the CNBC outlined the study objectives and outcomes, the data collection process and data management, the use of the data, and the expected benefits. Details about the study's aims and procedures were provided to each potential participant before joining the study 
are presented elsewhere ${ }^{(22)}$. Participants would provide verbal consent before responding anonymously, to the questionnaire. All the details above were also included in the first page of the questionnaire.

\section{Supplementary material}

For supplementary material accompanying this paper visit https://doi.org/10.1017/S1368980020004267

\section{References}

1. Mathus-Vliegen EM (1995) Healthy diet. Ned Tijdschr Tandheelkd 102, 189-193.

2. Sofi F, Macchi C, Abbate R et al. (2013) Mediterranean diet and health status: an updated meta-analysis and a proposal for a literature-based adherence score. Public Health Nutr 17, 2769-2782.

3. Kastorini CM, Milionis HJ \& Esposito Ket al. (2011) The effect of Mediterranean diet on metabolic syndrome and its components: A meta-analysis of 50 studies and 534,906 individuals. J Am Coll Cardiol 57, 1299-1313.

4. Willett WC (2006) The Mediterranean diet: science and practice. Public Health Nutr 9, 105-110.

5. Keys A, Menotti A, Karvonen MJ et al. (1986) The diet and 15-year death rate in the seven countries study. Am J Epidemiol 124, 903-915.

6. D'Alessandro A \& De Pergola G (2018) The Mediterranean Diet: its definition and evaluation of a priori dietary indexes in primary cardiovascular prevention. Int J Food Sci Nutr 69(6), 647-659. doi: 10.1080/09637486.2017.1417978.

7. Panagiotakos DB, Pitsavos C, Chrysohoou C et al. (2008) Five-year incidence of cardiovascular disease and its predictors in Greece: the ATTICA study. Vasc Med 13, 113-121.

8. Schwingshackl L \& Hoffmann G (2016) Does a Mediterranean-Type diet reduce cancer risk? Curr Nutr Rep 5, 9-17.

9. Scarmeas N, Luchsinger JA, Mayeux R et al. (2007) Mediterranean diet and Alzheimer disease mortality. Neurology 69, 1084-1093.

10. Féart C, Samieri C, Rondeau V et al. (2009) Adherence to a Mediterranean diet, cognitive decline, and risk of dementia. JAMA-J Am Med Assoc 302, 638-648.

11. Teljeur C, Smith SM, Paul G et al. (2013) Multimorbidity in a cohort of patients with type 2 diabetes. Eur J Gen Pract 19, $17-22$.

12. Prior A, Fenger-Grøn M, Larsen KK et al. (2016) The association between perceived stress and mortality among people with multimorbidity: a prospective population-based cohort study. Am J Epidemiol 184, 199-210.

13. Fortin M, Stewart M, Poitras ME et al. (2012) A systematic review of prevalence studies on multimorbidity: toward a more uniform methodology. Ann Fam Med 10, 142-151.

14. Nunes BP, Flores TR, Mielke GI et al. (2016) Multimorbidity and mortality in older adults: a systematic review and meta-analysis. Arch Gerontol Geriatr 67, 130-138.

15. Wang HHX, Wang JJ, Wong SYS et al. (2014) Epidemiology of multimorbidity in China and implications for the healthcare system: cross-sectional survey among 162,464 community household residents in southern China. BMC Med 12, 188.

16. Chen H, Chen Y \& Cui B (2018) The association of multimorbidity with healthcare expenditure among the elderly patients in Beijing, China. Arch Gerontol Geriatr 79, 32-38.
17. Mounce LTA, Campbell JL, Henley WE et al. (2018) Predicting incident multimorbidity. Ann Fam Med 16, 322-329.

18. Violan C, Foguet-Boreu Q, Flores-Mateo G et al. (2014) Prevalence, determinants and patterns of multimorbidity in primary care: a systematic review of observational studies. PLoS One 9, 3-11.

19. Marengoni A, Winblad B, Karp A et al. (2008) Prevalence of chronic diseases and multimorbidity among the elderly population in Sweden. Am J Public Health 98, 1198-1200.

20. De Carvalho JN, Roncalli ÂG, De Camargo Cancela $\mathrm{M}$ et al. (2017) Prevalence of multimorbidity in the Brazilian adult population according to socioeconomic and demographic characteristics. PLoS One 12, 1-13.

21. Van Oostrom SH, Picavet HSJ, De Bruin SR et al. (2014) Multimorbidity of chronic diseases and health care utilization in general practice. BMC Fam Pract 15, 1-9.

22. Kyprianidou M, Panagiotakos D, Faka A et al. (2020) Prevalence of multimorbidity in the Cypriot population; a cross-sectional study (2018-2019). PLoS One, 15(10), e0239835. doi: 10.1371/journal.pone.0239835.

23. Bountziouka V, Bathrellou E, Giotopoulou A et al. (2012) Development, repeatability and validity regarding energy and macronutrient intake of a semi-quantitative food frequency questionnaire: methodological considerations. Nutr Metab Cardiovasc Dis 22, 659-667.

24. Panagiotakos DB \& Pitsavos C (2008) Dietary patterns: a Mediterranean diet score and its relation to clinical and biological markers of cardiovascular disease risk. Nutr Metab Cardiovasc Dis 16, 559-568.

25. Johnston MC, Crilly M, Black C et al. (2019) Defining and measuring multimorbidity: a systematic review of systematic reviews. Eur I Public Health 29, 182-189.

26. Galbete C, Toledo E, Toledo JB et al. (2015) Mediterranean diet and cognitive function: the sun project. $J$ Nutr Health Aging 19, 305-312.

27. Kyriacou A, Evans JMM, Economides N et al. (2015) Adherence to the Mediterranean diet by the Greek and Cypriot population: a systematic review. Eur J Public Health 25, 1012-1018.

28. Hernández-Galiot A \& Goñi I (2017) Adherence to the Mediterranean diet pattern, cognitive status and depressive symptoms in an elderly non-institutionalized population. Nutr Hosp 34, 338-344.

29. Limongi F, Noale M, Gesmundo A et al. (2017) Adherence to the Mediterranean Diet and all-cause mortality risk in an elderly Italian population: data from the ILSA study. $J$ Nutr Heal Aging 21, 505-513.

30. Panagiotakos DB, Polystipioti A, Papairakleous $\mathrm{N}$ et al. (2007) Long-term adoption of a Mediterranean diet is associated with a better health status in elderly people; a cross-sectional survey in Cyprus. Asia Pac J Clin Nutr 16, 331-337.

31. Psaltopoulou T, Kyrozis A, Stathopoulos P et al. (2008) Diet, physical activity and cognitive impairment among elders: the EPIC-Greece cohort (European Prospective Investigation into Cancer and Nutrition). Public Health Nutr 11, 1054-1062.

32. Panagiotakos DB, Chrysohoou C, Pitsavos C et al. (2006) Association between the prevalence of obesity and adherence to the Mediterranean diet: the ATTICA study. Nutrition 22, 449-456.

33. Pingali P (2007) Westernization of Asian diets and the transformation of food systems: implications for research and policy. Food Policy 32, 281-298.

34. Huffman SL, Piwoz EG, Vosti SA et al. (2014) Babies, soft drinks and snacks: a concern in low- and middle-income countries? Matern Child Nutr 10, 562-574.

35. Martínez-González MA, García-López M, Bes-Rastrollo M et al. (2011) Mediterranean diet and the incidence of 
cardiovascular disease: a Spanish cohort. Nutr Metab Cardiovasc Dis 21, 237-244.

36. Stefler D, Malyutina S, Kubinova R et al. (2017) Mediterranean diet score and total and cardiovascular mortality in Eastern Europe: the HAPIEE study. Eur J Nutr 56, 421-429.

37. Herne S (1995) Research on food choice and nutritional status in elderly people: a review. Br Food J 97, 12-29.

38. Yannakoulia M, Panagiotakos D, Pitsavos C et al. (2008) Eating patterns may mediate the association between marital status, body mass index, and blood cholesterol levels in apparently healthy men and women from the ATTICA study. Soc Sci Med 66, 2230-2239.

39. Trichopoulou A, Bamia C \& Trichopoulos D (2009) Anatomy of health effects of Mediterranean diet: Greek EPIC prospective cohort study. BMJ 339, 26-28.

40. Dedoussis GV, Kanoni S, Mariani E et al. (2008) Mediterranean diet and plasma concentration of inflammatory markers in old and very old subjects in the ZINCAGE population study. Clin Chem Lab Med 46, 990. 